\title{
Determinants of self assessed health among Spanish older people living at home
}

\author{
Javier Damian, Ana Ruigomez, Vicente Pastor, Jose M Martin-Moreno
}

Department of Epidemiology and Biostatistics, National School of Public Health of Spain, "Instituto de Salud Carlos III", Madrid, Spain

J Damian

J M Martin-Moreno

Spanish Centre for Pharmacoepidemiologic Research, Madrid, Spain

A Ruigomez

"La Princesa" University Hospital, Madrid, Spain

V Pastor

Department of Preventive Medicine and Public Health.

"Universidad

Autonoma de

Madrid", Spain

V Pastor

J M Martin-Moreno

Correspondence to: Dr J M Martin-Moreno, Escuela Nacional de Sanidad, Instituto de Salud Carlos III, Sinesio Delgado 8 , 28029-Madrid, Spain.

\begin{abstract}
Study objective-To identify the main determinants of self assessed health among community dwelling elderly.

Participants and setting-A representative sample of 677 people aged 65 and over of the city of Madrid, Spain.

Design-Cross sectional study. Information was collected through personal interviews at the homes of the selected subjects. The five category dependent variable was grouped into two categories: good and poor self assessed health. Age, sex, social class, use of physician services, number of chronic conditions, and functional capacity, were included as main explanatory factors. Adjusted odds ratios were estimated through multiple logistic regression models.
\end{abstract}

Main results-A total of $49.5 \%$ of subjects rated their health as good or very good. Those aged 85 and over rated their health higher than those aged 65-74 (adjusted odds ratio (OR): $0.37 ; 95 \%$ confidence intervals (CI): $0.18,0.77$ ). The adjusted OR for an increase of three chronic conditions was 3.48 (95\% CI: 2.49, 4.85). Functional capacity also showed a strong independent effect (OR: 3.64; 95\% CI: $1.89,7.02)$. Social class was one of the main determinants for the youngest group, with those in the upper class reporting a better health perception (OR: $3.2895 \%$ CI: $1.70,6.35)$, but showed no effect in the oldest old (OR: $1.05 ; 95 \% \mathrm{CI}$ : $0.57,1.96)$.

Conclusions-Age, chronic conditions, and functional status were the main determinants of perceived health among Spanish elderly. The effect of social class on perceived health markedly decreases with age. This study may contribute to a better utilisation and interpretation of self ratings in research and in general practice.

(F Epidemiol Community Health 1999;53:412-416)

Self assessed health is a variable that is receiving growing attention in studies of all types and currently forms part of most surveys targeted at measuring the health status of populations or evaluating health related quality of life. ${ }^{1}$ There is ample evidence on the potential of this subjective measure to predict mortality independently of objective health condition ${ }^{2-6}$ but the mechanisms implicated in this phenomenon remain unclear. Similarly observed has been its ability to predict loss of functional capacity. ${ }^{78}$
In some instances self assessed health forms part of the main hypotheses but this is not the case in the majority of papers in which it appears, regardless of the specific focus of study. Self assessed health is being used in an ever increasing number of papers as a variable of adjustment, ${ }^{9-14}$ or is simply included as a covariate in a routine fashion, like age or sex. This being so, the complex field of study into its determinants calls for further in depth research.

With regard to the determinants of self assessed health among the elderly, the only factors that have shown a consistent association in most of the elderly populations studied are chronic conditions and functional status. Other factors such as age, sex, social class, marital status, and lifestyle habits, have been studied with very heterogeneous results in different countries, suggesting that the explanation for these differences may depend on cross cultural factors.

The main objective of this study is to identify the principal determinants of self assessed health among a representative sample of non-institutionalised elderly people in the Madrid metropolitan area, Spain. There is a substantial body of research on aging showing that old persons are a very heterogeneous population. More specifically, there is extensive evidence showing important differences by age and sex. Thus, we also carried out a separate analysis of the pattern of determinants by age group and by sex.

\section{Methods}

This study uses data from a survey conducted in the period May 1994-March 1995. The sampling frame comprised all noninstitutionalised persons aged 65 or older who were registered on the Madrid Municipal Roll. A sample of 1001 people was obtained. Random sampling was carried out with proportional stratification by sex and municipal district. To ensure that the sample contained a sufficient number of persons from the oldest age groups, non-proportional age stratification, with three equal sized strata were selected (65$74,75-84$, and 85 and over).

A structured questionnaire was used to collect information. Interviews were conducted at the homes of selected subjects, by adequately trained social workers. For the purposes of the analyses presented here, subjects on whom information had been gathered via proxies were excluded. The main variables covered by this study are described in greater detail below. 
SELF ASSESSED HEALTH

This variable was evaluated by the question: In general terms, How would you describe your health: very good, good, fair, poor or very poor? A card, supplied to interviewers showing the alternatives, was used to facilitate the reply process. No health related questions that could influence the response choice were made before asking people to rate their health (the preceding questions were: age, marital status, living arrangements and family members).

CHRONIC CONDITIONS

Subjects were asked whether they suffered from any of the following chronic conditions: osteoarthritis or rheumatism, bronchitis or asthma, deafness, diabetes, prostate disorders, high blood pressure, heart diseases, nervous problems or depression, cataracts, other eyesight related problems, varicose veins in the legs, difficulty holding urine, hip fracture, stroke, and cancer. In case of a positive answer interviewers were encouraged to obtain from the respondents a confirmation that the doctor had said that they suffered from this specific condition.

\section{PHYSICIAN CONTACT}

Subjects were asked whether they had contacted a physician in the previous two weeks.

SOCIAL CLASS

An adapted version of the British occupationbased social class classification was used in conjunction with the 1979 Spanish National Classification of Occupations. ${ }^{15}$ In this study, subjects were classified as manual or nonmanual workers.

FUNCTIONAL STATUS

Subjects were asked as to the degree of difficulty experienced in performing the following basic activities of daily living (ADL) for themselves: eating, going to the toilet, bathing or showering, dressing/undressing, standing up/sitting down, walking, going outdoors, shaving/brushing and combing their hair, and use of stairs. In this study, subjects were classified into the following three mutually exclusive categories: (1) Able in all ADL; (2) Able with difficulty in at least one ADL; and (3) Unable in at least one ADL.

Because of the sampling format used, a weighting variable was created (see appendix). All analyses used these weights to re-establish proportionality of age except in those cases where results are shown as stratified by age group.

One main logistic regression model was constructed in which the five categories of the dependent variable were grouped to two: (1) Self assessed good health (the result of combining the "very good" and "good" categories); (2) Self assessed poor health (the result of combining the "fair", "poor" and "very poor" categories). The following independent variables were included in the model: sex, age (three groups), physician contact, social class, number of chronic conditions (as a continuous variable) and functional status. We further explored the impact on the main model coefficients of some other variables potentially related with self perceived health such as smoking status, alcohol intake, body mass index (BMI), any drug consumption in the previous two weeks, hospital admission in the previous year and living arrangements (with others/alone). To evaluate potential differences by age and sex, multiple logistic regression models were computed separately for each age group and sex category, including the main variables.

Pearson's $\chi^{2}$ test was used for comparison of proportions and the $t$ test for comparison of means. All $\mathrm{p}$ values are two tailed. Analyses were run using the SPSS/PC+ 4.0 statistical software package.

\section{Results}

Of the initial sample of 1001 people, 196 refused to participate and 33 could not be located or failed to provide reliable information. The study sample comprised 772 people, with an overall response rate of $79.8 \%$. In this study, we excluded 95 interviews answered by proxies, making the final number of subjects studied 677.

Table 1 shows certain sample characteristics. The mean (SD) age was 74.0 (6.73). A total of $49.5 \%$ of the population rated their health status as "good" or "very good". The proportion of women who lived alone was notably higher than that of men $(23.9 \% \vee 5.2 \%, \mathrm{p}<0.001)$. Use of physician services was also higher among women than among men $(40.5 \% v$ $32.8 \%, \mathrm{p}=0.042)$. Prevalence of functional impairment in one or more basic ADL was higher in women than in men $(16.9 \% v 6.8 \%$, $\mathrm{p}<0.001)$. A high prevalence of chronic conditions was observed: $81.5 \%$ of subjects stated that they suffered from two or more chronic conditions. The mean (SD) number of chronic conditions was 3.3 (1.9), being 3.5 (1.9) for women and 2.9 (1.9) for men $(\mathrm{p}<0.001)$.

Table 2 presents the results of the logistic regression analysis in which all the main variables were included. The number of chronic conditions and functional status were strongly associated with self assessed health.

Table 1 Characteristics of study participants (\%)

\begin{tabular}{lr}
\hline Sex (\% women) & 62.2 \\
Age & \\
$\quad 65-74$ & 60.5 \\
$75-84$ & 31.8 \\
$85+$ & 7.7 \\
Self assessed health & 7.7 \\
Very good & 41.8 \\
Good & 36.6 \\
Fair & 10.3 \\
Poor & 3.6 \\
Very poor & 16.8 \\
Living alone & 37.6 \\
Physician contact & 60.0 \\
Social class (\% manual workers) & \\
Functional status & 60.4 \\
Able in all ADL & 26.6 \\
Difficulty in 1 or more ADL & 13.0 \\
Unable in 1 or more ADL & \\
Number of chronic conditions & 4.7 \\
0 & 13.8 \\
1 & 57.0 \\
$2-4$ & 24.5 \\
$>4$ & \\
\hline
\end{tabular}


Table 2 Factors associated with poor self rated health

\begin{tabular}{|c|c|c|c|}
\hline & $\begin{array}{l}\text { Crude } \\
\text { OR }\end{array}$ & $\begin{array}{l}\text { Adjusted } O R^{\star} \\
(95 \% C I) \quad(n=653)\end{array}$ & $\begin{array}{l}\text { Adjusted OR }+ \\
(95 \% C I) \quad(n=652)\end{array}$ \\
\hline \multicolumn{4}{|l|}{ Sex } \\
\hline Men & 1 & & \\
\hline Women & 1.72 & $1.25(0.87,1.80)$ & $1.17(0.81,1.69)$ \\
\hline \multicolumn{4}{|l|}{ Age } \\
\hline $65-74$ & 1 & & \\
\hline $75-84$ & 1.19 & $0.85(0.57,1.27)$ & $0.88(0.59,1.31)$ \\
\hline $85+$ & 0.97 & $0.37(0.18,0.77)$ & $0.43(0.21,0.90)$ \\
\hline \multicolumn{4}{|l|}{ Social class } \\
\hline Non-manual & 1 & & \\
\hline Manual & 2.60 & $1.98(1.39,2.83)$ & $1.82(1.26,2.61)$ \\
\hline \multicolumn{4}{|l|}{ Physician contact } \\
\hline No & 1 & & \\
\hline Yes & 3.07 & $2.26(1.56,3.26)$ & $2.39(1.65,3.48)$ \\
\hline \multicolumn{4}{|l|}{ Number of chronic conditions } \\
\hline 1-unit increase & 1.68 & $1.52(1.36,1.69)$ & $1.36(1.20,1.53)$ \\
\hline 3-unit increase & 4.78 & $3.48(2.49,4.85)$ & $2.50(1.74,3.61)$ \\
\hline \multicolumn{4}{|l|}{ Functional status } \\
\hline Able in all ADL & 1 & & \\
\hline Difficulty in 1 or more ADL & 3.55 & $2.19(1.42,3.36)$ & $2.01(1.29,3.13)$ \\
\hline Unable in 1 or more ADL & 5.17 & $3.64(1.89,7.02)$ & $3.62(1.87,7.03)$ \\
\hline \multicolumn{4}{|l|}{ Nervous problems and depression } \\
\hline No & 1 & & \\
\hline Yes & 6.52 & & $3.67(2.36,5.70)$ \\
\hline
\end{tabular}

*Adjusted for the variables of the table. Number of chronic conditions has been included in the model as continuous variable (shown are estimated odds ratios for an increase of 1 and 3 conditions). †Additionally adjusted for nervous problems and depression.

Table 3 Factors associated with poor self rated health by age group

\begin{tabular}{|c|c|c|c|}
\hline & $\begin{array}{l}65-74(n=256) \\
O R^{\star}(95 \% C I)\end{array}$ & $\begin{array}{l}75-84(n=267) \\
O R^{\star}(95 \% C I)\end{array}$ & $\begin{array}{l}85+(n=249) \\
O R^{\star}(95 \% C I)\end{array}$ \\
\hline \multicolumn{4}{|l|}{ Sex } \\
\hline Men & 1 & 1 & 1 \\
\hline Women & $1.63(0.85,3.14)$ & $0.90(0.48,1.68)$ & $0.66(0.31,1.39)$ \\
\hline \multicolumn{4}{|l|}{ Social class } \\
\hline Non-manual & 1 & 1 & 1 \\
\hline Manual & $3.28(1.70,6.35)$ & $1.12(0.61,2.07)$ & $1.05(0.57,1.96)$ \\
\hline \multicolumn{4}{|l|}{ Physician contact } \\
\hline No & 1 & 1 & 1 \\
\hline Yes & $2.69(1.37,5.27)$ & $2.16(1.18,3.97)$ & $0.98(0.50,1.90)$ \\
\hline \multicolumn{4}{|l|}{ Number of chronic conditions } \\
\hline 1-unit increase & $1.74(1.41,2.16)$ & $1.35(1.13,1.62)$ & $1.23(1.04,1.46)$ \\
\hline 3-unit increase & $5.29(2.77,10.10)$ & $2.49(1.46,4.24)$ & $1.88(1.13,3.12)$ \\
\hline \multicolumn{4}{|l|}{ Functional status } \\
\hline Able in all ADL & 1 & 1 & 1 \\
\hline Difficulty in 1 or more ADL & $1.67(0.74,3.74)$ & $3.36(1.74,6.49)$ & $1.13(0.46,2.79)$ \\
\hline Unable in 1 or more ADL & $3.06(0.58,16.14)$ & $5.68(2.20,14.64)$ & $2.04(0.86,4.86)$ \\
\hline
\end{tabular}

${ }^{\star}$ Adjusted for the variables of the table. Number of chronic conditions has been included in the model as continuous variable (shown are estimated odds ratios for an increase of 1 and 3 conditions).

Table 4 Factors associated with poor self rated health by sex

\begin{tabular}{|c|c|c|}
\hline & $\begin{array}{l}\operatorname{Men}(n=233) \\
O R^{\star}(95 \% C I)\end{array}$ & $\begin{array}{l}\text { Women }(n=420) \\
\text { OR } R^{\star}(95 \% C I)\end{array}$ \\
\hline \multicolumn{3}{|l|}{ Age group } \\
\hline $65-74$ & 1 & 1 \\
\hline $75-84$ & $1.31(0.71,2.42)$ & $0.63(0.37,1.08)$ \\
\hline $85+$ & $0.77(0.20,2.96)$ & $0.26(0.11,0.63)$ \\
\hline \multicolumn{3}{|l|}{ Social class } \\
\hline Non-manual & 1 & 1 \\
\hline Manual & $2.08(1.18,3.67)$ & $1.97(1.24,3.14)$ \\
\hline \multicolumn{3}{|l|}{ Physician contact } \\
\hline No & 1 & 1 \\
\hline Yes & $1.88(1.05,3.38)$ & $2.50(1.55,4.04)$ \\
\hline \multicolumn{3}{|l|}{ Number of chronic conditions } \\
\hline 1 -unit increase & $1.47(1.24,1.74)$ & $1.54(1.33,1.79)$ \\
\hline 3-unit increase & $3.15(1.88,5.27)$ & $3.66(2.35,5.70)$ \\
\hline \multicolumn{3}{|l|}{ Functional status } \\
\hline Able in all ADL & 1 & 1 \\
\hline Difficulty in 1 or more ADL & $1.79(0.87,3.65)$ & $2.47(1.43,4.25)$ \\
\hline Unable in 1 or more ADL & $3.40(0.88,13.18)$ & $4.40(2.01,9.65)$ \\
\hline
\end{tabular}

^Adjusted for the variables of the table. Number of chronic conditions has been included in the model as continuous variable (shown are estimated odds ratios for an increase of 1 and 3 conditions).

Those over the age of 85 perceived their health as being appreciably better than did younger participants, once the main variables had been controlled for (odds ratio (OR): 0.37). On additional adjustment being made for nervous
KEY POINTS

- The oldest old perceive their health clearly better than younger people when the relevant variables have been controlled for.

- Social class is a strong independent determinant of self assessed health in Spanish elderly, but this effect progressively disappears with age.

- In general, the pattern of determinants of self assessed health is similar to that of other populations with sociocultural and health system differences.

- Geriatricians and general practitioners must take into account these determinants when interpreting health perceptions of their patients.

problems and depression, only a slight dilution of the previous effects was observed, except for the case of physician contact, which showed a stronger effect.

We further explored the impact exerted in this main model by other variables: smoking status, body mass index (BMI), drug consumption in the previous two weeks, hospital admission in the previous year and living arrangements. None of these variables substantially modified the estimators of the main model except BMI: a clear improvement in the better self perception of the oldest group with respect to the youngest was obtained when BMI was included (the previous OR of 0.43 changed to 0.25; 95\% CI: 0.10, 0.56).

Table 3 shows the results of the analysis stratified by age group. In general, the effect exerted by the main variables on health perception tends to decrease markedly as age increases. The effect of social class diminishes in importance with age, proving one of the major determinants of health perception in the youngest but showing no effect in the oldest group. A similar pattern can be noticed with respect to physician contact. For the oldest age group, the determinants of self rated health were basically limited to the number of chronic conditions and ADL disability. In this age group, difficulty in any ADL seemed to have little effect on health perception. Table 4 presents the results of the analysis stratified by sex. Practically all the effects were stronger for women.

\section{Discussion}

The principal determinants of self assessed health found in this study were number of chronic conditions and functional status. In addition to these determinants - both linked to physical health - a strong age effect and a marked interaction between age and social class were also observed.

The prevalence of chronic conditions was substantially high in this population $(81.5 \%$ suffered from two or more chronic conditions). The number of chronic conditions is one of the clearest determinants of self assessed health in almost all studies conducted on older persons. This was confirmed in our study population, 
with an adjusted OR of 3.48 for an increase of three chronic conditions. A high prevalence of impairment in unaided performance of one or more ADL was also observed (13.0\%). This variable was another of the principal determinants of self assessed health, particularly in the middle age group (adjusted OR: 5.68).

Our study showed that women had a worse perception of their health than men, a finding that has been reported in a number of studies, both in Spain ${ }^{16}$ and elsewhere. ${ }^{18-20}$ Women, not only suffered from a greater number of chronic conditions and disabilities, but also tended to experience more nervous disorders and depressions. In our study, we observed that this effect was considerably reduced (OR: 1.17) when adjustment was made for these variables and for others, such as age, social class, and use of medical services. Indeed, in the 85 and over age group the effect became inverted, with women having better perception (OR: 0.66). There are also studies that showed no meaningful differences ${ }^{21} 22$ or even a poorer perception by men. ${ }^{23-25}$ As for the remaining sex related determinants in our study, the only aspect worthy of note was the relatively greater effect of the physician contact variable for women.

With respect to age, the crude results showed no meaningful differences in self assessed health except for a slightly more pessimistic outlook in the middle compared with the youngest age group. However, when the effect of the remaining variables was controlled for, an important change was observed: self perception of health was clearly better among the oldest compared with the youngest group (OR: $0.37)$. However, we have found that this effect is only applicable to women (table 4). Although the magnitude of this effect is very high in our population, this same phenomenon has been observed in other studies ${ }^{25-27}$ and seems to respond to a process of adaptation to, or acceptance of, comorbidity and disabilities as normal in the aging process. In a study with longitudinal data, Idler ${ }^{25}$ has shown that, in addition to this mechanism, two other explanations seem to apply: (1) a cohort effect, in that differences are not attributable to age changes but to different life experiences of the cohorts, and (2) a selective survivorship: those with poor health perceptions and greater risk of mortality leave the cohort.

Examination of the pattern of determinants in each age group brings to light a number of noteworthy facts (table 3 ). The effect of social class is markedly modified by age-that is, whereas social class is an important determinant among the youngest group, no such social class related differences are observable among the oldest group. To our knowledge no other study has run a comparable analysis against which this finding could be compared. Again it is also possible a cohort effect as an explanation of this finding, possibly involving meaningful differences in levels of education among cohorts. It should be noted that for all variables studied, the estimates are compatible with a pattern of dilution of effect with advancing age, with the exception of functional status that showed the strongest effect in the middle age group.

As regards social class (measured here by occupation), a considerable effect was observed. Lower class persons tended to have a worse perception of their health (adjusted OR: 1.98). This effect was not explained by possible differences in lifestyle variables like alcohol consumption, tobacco use, body mass index, and consumption of medicines. We believe that differences in the actual state of health between manual and non-manual workers are well controlled by the variables included in the model, but some degree of residual confounding is also possible. The association between self perceived poor health and social class has been observed in other studies independently of the variable used, be it occupation, ${ }^{22} 28$ income level ${ }^{19}$ or education. ${ }^{22}{ }^{24}$

Another leading determinant of self assessed health is use of physician services. Inclusion of this variable was considered important as a potential confounder, as it allows to control for several factors linked both to current objective health and to symptoms and minor ailments but, because of the cross sectional nature of the study, the interpretation of the estimates is complicated. In fact, there may be a two way effect, in that poor perception of health may lead to use of medical services or, conversely, recent use of medical services may induce to make a worse assessment. Studies reporting results adjusted for functional capacity also found a strong association. ${ }^{29-31}$

Certain considerations should be borne in mind when interpreting these results. Firstly, it should be pointed out that the estimates might be affected by a certain degree of residual confounding, because of the failure to include a given variable. Some measure of disease severity would have improved the adjustment. Another variable that could arguably have certain weight is the functional capacity in Instrumental Activities of Daily Living. This variable could not be included in this study because of the high number of missing values. Even so, we believe that the effects found are strong enough to be explained by the lack of inclusion of this or other variables. A further consideration is that all the information was gathered on a self reporting basis and, though there is evidence of this method's reliability as compared with physician-based assessments, ${ }^{32-34}$ it could give rise to a certain degree of overestimation as regards the real effect of morbidity or disability on perceived health.

To conclude, the general pattern of determinants of self assessed health observed in Spanish elderly people diverges little from that observed in other elderly populations with apparent cultural differences. The most notable differences are linked to the surprising variety of age related effects, particularly those related with social class. Our study confirms the growing body of evidence pointing to the fact that the oldest old are a subgroup that behaves very differently and that any purported study into perception of health within this group ought to adopt a suitably modified 
approach. Finally it should be remembered that results must be generalised to populations that can make a self assessment of their health. These populations are healthier than the total elderly population, because of the exclusion of proxies. These differences may become substantial in the case of the oldest old, a group with a high proportion of proxy interviews.

\section{Appendix}

For each age group (65-74, 75-84, 85+) weights for statistical analysis were computed by using the following formula:

$$
\mathrm{w}_{\mathrm{i}}=\frac{\mathrm{t} / \mathrm{T}}{\mathrm{n}_{\mathrm{i}} / \mathrm{N}_{\mathrm{i}}}
$$

Where:

$\mathrm{w}_{\mathrm{i}}$ : Weight for $\mathrm{i}^{\text {th }}$ age group

t: Total number of subjects in the sample

$\mathrm{T}$ : Total number of subjects in the population

$\mathrm{n}_{\mathrm{i}}$ : Number of subjects in $\mathrm{i}^{\text {th }}$ age group in the sample

$\mathrm{N}_{\mathrm{i}}$ : Number of subjects in $\mathrm{i}^{\text {th }}$ age group in the population. The authors wish to thank Drs Juan Donado, Salud Palenzuela,
and Pedro Aldama for their helpful contribution in different phases of this research, and Drs Pearl S German, Sam Shapiro phases of this research, and Drs Pearl S German, Sam Shapiro versions of the manuscript

Funding: this study was supported by grant $93 / 0159$ from the Spanish "Fondo de Investigación Sanitaria".

Conflicts of interest: none.

1 Ware JE. The status of health assessment 1994. Annu Rev Public Health 1995;16:327-54.

2 Mossey JM, Shapiro E. Self-rated health: a predictor of mortality among the elderly. Am F Public Health 1982;72: 800-8.

3 Kaplan GA, Barell V, Lusky A. Subjective state of health and survival in elderly adults. $\mathcal{F}$ Gerontol 1988;43:S114-20.

4 Idler EL, Kasl S. Health perceptions and survival: do global evaluations of health status really predict mortality? $\mathscr{F}$ Gerevaluations of health

5 Pijls LT, Feskens EJ, Kromhout D. Self-rated health, mortality, and chronic diseases in elderly men. The Zutphen Study, 1985-1990. Am f Epidemiol 1993;138: $840-8$

6 Appels A, Bosma H, Grabauskas V, et al. Self-rated health and mortality in a Lithuanian and a Dutch population. So Sci Med 1996;42:681-9.

7 Idler EL, Kasl SV. Self-ratings of health: do they also predict change in functional ability? F Gerontol B Psychol Sci Soc Sci 1996;50B:S344-53

8 Mor V, Wilcox V, Rakowski W, et al. Functional transitions among the elderly: patterns, predictors, and related hospital use. Am F Public Health 1994;84:1274-80.

9 Rakowski W, Hickey T. Mortality and the attribution of health problems to aging among older adults. Am $\mathcal{F}$ Public Health 1992;82:1139-41.
10 Scott WK, Macera CA, Cornman CB, et al. Functional health status as a predictor of mortality in men and women health status as a predictor of mortality in

11 Bograd H, Ritzwoller DP, Calonge N, et al. Extending health maintenance organization insurance to the uninsured. A controlled measure of health care utilization. $\mathcal{F} A M A$ 1997; 277:1067-72

12 Pahor M, Guralnik JM, Corti MC, et al. Long-term survival and use of antihypertensive medications in older persons. $\mathcal{F}$ Am Geriatr Soc 1995;43:1191-7.

13 Seidlitz L, Duberstein PR, Cox C, et al. Attitudes of older people toward suicide and assisted suicide: an analysis of Gallup Poll findings. F Am Geriatr Soc 1995;43:993-8.

14 Vatten LJ, Holmen J, Kruger O, et al. Low blood pressure and mortality in the elderly: a 6 -year follow- up of 18,022 Norwegian men and women age 65 years and older. Epidemiology 1995;6:70-3.

15 Domingo Salvany A, Marcos Alonso J. Propuesta de un indicador de la "clase social" basado en la ocupación. Gac Sanit 1989;3:320-6.

16 Perula de Torres LA, Martinez de la Iglesia J, Ruiz Moral R, et al. Variables relacionadas con el estado de salud autopercibido: estudio poblacional. Aten Primaria 1995;16: autopercib

17 Zunzunegui MV, Béland F. La salud de las personas mayores de Leganés. Rev Gerontol 1995;5:245-58.

8 Murray J, Dunn G, Tarnopolsky A. Self-assessment of health: an exploration of the effects of physical and psychological symptoms. Psychol Med 1982;12:371-8.

19 Cairney J, Arnold R. Social class, health and aging: socioeconomic determinants of self-reported morbidity among the non-institutionalized elderly in Canada. Can $\mathcal{7}$ Public Health 1996;87:199-202.

20 Barberger Gateau P, Chaslerie A, Dartigues JF, et al. Health measures correlates in a French elderly community population: the PAQUID study. F Gerontol 1992;47:S8895.

21 Moum T. Self-assessed health among Norwegian adults. Soc Sci Med 1992;35:935-47.

22 Liang J, Bennett J, Whitelaw N, et al. The structure of selfreported physical health among the aged in the United States and Japan. Med Care 1991;29:1161-80.

23 Ferraro KF. Self-ratings of health among the old and the old-old. F Health Soc Behav 1980;21:377-83.

24 Johnson RJ, Wolinsky FD. The structure of health status among older adults: disease, disability, functional limitation, and perceived health. F Health Soc Behav 1993;34: 105-21

25 Idler EL. Age differences in self-assessments of health: age changes, cohort differences, or survivorship? f Gerontol 1993;48:S289-300.

26 Lichtenstein RL, Thomas JW. A comparison of selfreported measures of perceived health and functional health in an elderly population. $\mathcal{F}$ Community Health 1987; 12:213-30.

27 Goldstein M, Siegel JM, Boyer R. Predicting changes in perceived health status. Am 7 Public Health 1984;74:61114.

28 Arber S, Ginn J. Gender and inequalities in health in later life. Soc Sci Med 1993;36:33-46.

29 Wolinsky FD, Johnson RJ. The use of health services by older adults. F Gerontol B Psychol Sci Soc Sci 1991;46:S345-7.

30 Mutchler JE, Burr JA. Racial differences in health and health care service utilization in later life: the effect of socioeconomic status. F Health Soc Behav 1991;32:342-56.

31 Blaum CS, Liang J, Liu X. The relationship of chronic diseases and health status to the health services utilization of older Americans. $\mathcal{7}$ Am Geriatr Soc 1994;42:1087-93.

32 Ford AB, Folmar SJ, Salmon RB, et al. Health and function in the old and very old. 7 Am Geriatr Soc 1988;36:187-97.

33 Bush TL, Miller SR, Golden AL, et al. Self-report and medical record report agreement of selected medical conditions in the elderly. Am F Public Health 1989;79:1554-6.

34 Kriegsman D, Pennix B, van Eijk J, et al. Self-reports and general practitioner information on the presence of chronic diseases in community dwelling elderly. $\mathcal{f}$ Clin Epidemiol 1996;49:1407-17. 